\title{
The Polytraumatized in the Emergency Hosting Service and the Service of Resuscitation Gabriel Touré Mali
}

\author{
Diop Thierno Madane ${ }^{1 *}$, Magane Moustapha Issa', Almeimoune Abdoulhamidou1, \\ Dembélé AlajiSeidou ${ }^{2}$, Dabo Aminata ${ }^{1}$, Ouattara Kassoum¹, Dembélé Bakary Tientigui ${ }^{3}$, \\ Traoré Alhassane ${ }^{3}$, Togo Adegné ${ }^{3}$, Diango Mahamane Djibo ${ }^{1}$ \\ ${ }^{1}$ Department Anesthesia-Intensive Care and Emergency, Gabriel Toure University Hospital, Bamako, Mali \\ ${ }^{2}$ Anesthesia Department Ophthalmological Institute, West African University Hospital, Bamako, Mali \\ ${ }^{3}$ General Surgery Department, Gabriel Toure University Hospital, Bamako, Mali \\ Email: *madane.diop@gmail.com
}

How to cite this paper: Madane, D.T., Issa, M.M., Abdoulhamidou, A., AlajiSeidou, D., Aminata, D., Kassoum, O., Tientigui, D.B., Alhassane, T., Adegné, T. and Djibo, D.M. (2018) The Polytraumatized in the Emergency Hosting Service and the Service of Resuscitation Gabriel Touré Mali. Surgical Science, 9, 157-163.

https://doi.org/10.4236/ss.2018.94018

Received: March 19, 2018

Accepted: April 25, 2018

Published: April 28, 2018

Copyright $\odot 2018$ by authors and Scientific Research Publishing Inc. This work is licensed under the Creative Commons Attribution International License (CC BY 4.0).

http://creativecommons.org/licenses/by/4.0/

\begin{abstract}
Summary: Polytrauma is the leading cause of death in the under-40 population. They are accompanied by major morbidity with severe sequelae. The polytraumatized is defined as a serious trauma with several bodily injuries, at least one of which is life-threatening in the very short term. The initial hospital care must not barely delay and directly affect the prognosis. In developing countries, the absence of pre-hospital medicine means that mortality is still very high, which leads us to initiate this work, which aims to study the epidemiological and clinical aspects of polytrauma in emergency and in resuscitation of Gabriel Toure University Hospital. Material and Methods: This was a retrospective study that took place over a period of ten (10) months from February to November 2016. We included all patients received for polytrauma emergency hosting service. The data were collected using a surveycard. Results: During our study period, we collected a total of 200 polytraumatized cases out of a total of 16,141 patients admitted to the emergency hosting service, a prevalence of $1.3 \%$. The age group of $20-29$ years was the most represented with average age of 32.39 years. The male sex was predominant with $65 \%$ with a sex ratio of 1.9 . The students were the most represented with $24 \%$. The trauma occurred at $22.5 \%$ between $8: 00$ and 12:00 am, the public road was the main place of the trauma with $57.5 \%$ of the cases. Two-wheeled vehicles were involved in the accident in $68.9 \%$ of cases. The delay between trauma and admission was minus 6 hours in $70.5 \%$ of cases, $15.5 \%$ had a Glasgow lessthan $8 \%$ and $44.5 \%$ PAS $<90 \mathrm{mmHg}$. The polytrauma associated with a cranial + limb and cranial + abdominal were the
\end{abstract}


most represented with respectively $37.5 \%$ and $25 \%$. The damage control suegery was performed in $79 \%$ of patients. The mortality was $31 \%$ and hemorrhagic shock was the most common etiology of these deaths with $51.6 \%$. Conclusion: The polytrauma is clinical situation putting the patients vital prognosis at stake. The haemorrhage is the origin of the student mortality. The installation of rigorous diagnostic system and a pre-hospital medicine will reduce the morbi-mortality.

\section{Keywords}

Polytraumatized, Emergency, Resuscitation, Bamako, Mali

\section{Introduction}

Injuries represent the 4 th leading cause of all-age mortality and the leading cause of death in the under-40 population [1] [2]. The polytraumatized is defined as a severely traumatized person with several bodily injuries, at least one of which is life-threatening in the very short term [3]. Haemorrhagic shock alone is responsible for $40 \%$ mortality in these patients within 48 hours of trauma [4]. According to the World Health Organization (WHO), injury deaths are twice as high in low-income countries as in high-income countries [5]. The initial hospital care of such patients is immediate and the diagnostic and therapeutic approach must be extremely rigorous. It must be done according to a real strategy in order to determine the therapeutic urgency and to establish the complete lesional balance sheet. The adequacy and speed of the implementation of this strategy directly affect the prognosis of the polytraumatized. In sub-Saharan Africa, according to WHO, injuries are responsible for more deaths and disabilities than malaria and AIDS [5]. A study in Guinea found $39.54 \%$ polytrauma [6]; in Mali another had found 9.7\% polytraumatized [7]. In Mali, with the multiplication of vehicles; non-compliance with traffic rules, the absence of pre-hospital medicine and a social security system (social third-party payment) means that mortality is still very high. As a result, the issue of medical management of polytrauma remains a public health problem. For a better knowledge of the subject, to improve the management of polytrauma patients, We initiated this work in order to study the epidemiological and clinical aspects of polytrauma in the emergency department and resuscitation of GabrielToure University Hospital.

\section{Material and Methods}

This was a retrospective study that took place over a ten (10) month period from February to November 2016. The study to be carried out on all patients admitted for trauma to the emergency hosting service. We included all patients admitted to the emergency department for polytrauma, that is, any patient with at least two traumatic injuries.at least one of which was life-threatening. Patients 
admitted for non-life-threatening trauma, patients with only one traumatic injury and trauma patients who died before care were not selected. The following parameters were analyzed: age, sex, etiology, time elapsed in the prehospital phase, diagnosis, treatment and evolution. The data was collected using a survey sheet, captured and analyzed using IBM's software, SPSS Statistics 22.0., Microsoft Office Pack 2016 software. The results are presented through simple tables, crosstabs and graphs.

\section{Results}

During our study period, we collected a total of 200 polytrauma cases out of a total of 16,141 patients admitted to emergency hosting service (EHS), a prevalence of $1.3 \%$. The age group of 20 to 29 yearswas the most represented with an average of 32.39 years. The male sex was predominant with $65 \%$ with a sex ratio of 1.9. The students/students were the most represented with $24 \%$. The trauma occurred at 22.5\% between 8:00 and 12:00 am, the circumstances of the trauma (Table 1). The two-wheeled machines were involved in the accident in $68.9 \%$ of cases. The delay between trauma and admission was less than 6 hours in $70.5 \%$ of cases, $15.5 \%$ had a Glasgow less than 8 and $44.5 \%$ PAS $<90 \mathrm{mmHg}$. Lesions found in traumatized patients (Table 2). The nature of the treatment achieves (Figure 1). The evolution of the traumatized is detailed in (Table 3). Hemorrhagic shock was the most common etiology of these deaths with 51.6\%.

Table 1. Etiology of trauma.

\begin{tabular}{ccc}
\hline Cause of trauma & Frequency & Percentage \% \\
\hline Public road accident & 115 & 57.5 \\
Voluntary knocks and blows & 35 & 17.5 \\
Work accident & 27 & 13.5 \\
Domestic accident & 14 & 7.0 \\
Other & 9 & 4.5 \\
Total & 200 & 100 \\
\hline
\end{tabular}

The accidents of the public road was the mostfrequent cause of polytraumatisme with $57.5 \%$.

Table 2. Type of lesions.

\begin{tabular}{ccc}
\hline Type of polytrauma & Frequency & Percentage $\%$ \\
\hline Cranial + Member & 75 & 37.5 \\
Cranial + Abdominal & 50 & 25.0 \\
Thoracic + Abdominal & 34 & 17.0 \\
Member + Abdominal & 26 & 13.0 \\
Cranial + Thoracic & 7 & 3.5 \\
Member + Thoracic & 6 & 3.0 \\
Abdominal + Member + Thoracic & 2 & 1.0 \\
Total & 200 & 100 \\
\hline
\end{tabular}

The cranial/member and cranial/abdominalwerethe mostfrequentinjury with respectively $37.5 \%$ and $25 \%$. 
Table 3. Evolution of traumatized.

\begin{tabular}{ccc}
\hline Evolution & Frequency & Percentage \% \\
\hline Transfer & 93 & 46.5 \\
Death & 62 & 31.0 \\
Exit & 36 & 18.0 \\
Discharge & 9 & 4.5 \\
Total & $\mathbf{2 0 0}$ & $\mathbf{1 0 0}$ \\
\hline
\end{tabular}

We noted a mortality of $31 \%$.

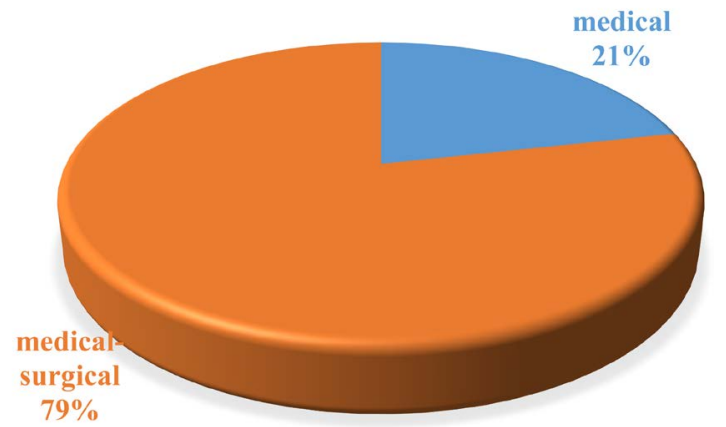

Figure 1. Type of treatmentperformed. The damage control surgery was performed in $79 \%$ of patients.

\section{Discussion}

During our study we encountered some technical difficulties because of the absence of pre-hospital medicine, so no real information transmission on pre-hospital phases of trama. During the study period, we collected a total of 200 polytraumatized cases out of a total of 16,141 patients admitted to the emergency hosting service, a prevalence of 1.3\%. Diango et al. [7] and Mangane et al. [8] found respectively $53.4 \%$ and $58.8 \%$ of traumatized. Our result could be explained by the fact that we included only the polytraumatized and also by the fact that many polytraumatized died at the place of the accident or during the transpor. In our study the average age of our patients was 32.39 years with extremes ranging from 2 to 66 years and the most represented age group was that of 20 to 29 years with $44 \%$ of cases. Our results are similar to those of Diango et al. [7] and Mangane et al. [8] found respectively, 43\% for 15 - 29 years, $27.50 \%$ for 12 - 19 years. Thes results can be explained by the fact that those under 40 are the most active segment of the population and the most affected by violent trauma.

We found a sex ratio of 1.9 in favor of the male sex (65\%). This male predominance was found in the studies; Coulibaly et al. in Mali [9] 75\%, Bahloul et al. in Tunisia [10] 90\%, Wu et al. in China [11] 76.6\%, Privat et al. [12] in France $83.3 \%$. This may be explained by the fact that men drive more than women and occupy risky occupations such as those of vehicle drivers and have risky behaviors that women: driving at high speed, drunk driving on the road. 
During our study accidents on public road swith $57.5 \%$ was the main cause of the trauma, this finding is widely found in the literature. Mangane et al. [8], Kanikomo et al. [13] found respectively $74.40 \%, 59.7 \%$, accident of the public road. This high rate of accidents of the public road as aetiologies of multiple trauma could be explained by the increase in road traffic and the fleet of two-wheeled vehicles and cars, the poor quality of gear and the lack of control of the high way code. Two-wheeled vehicles were involved in accidents of the public road with $68.9 \%$ of cases. This significant proportion of motor cyclists involved in accidents of the public road wasalsoobserved in the literature with $67.5 \%$ in Benin [14], 64.5\% in Taiwan [15], and 72\% in Thailand [16]. This result could be explained by the uncontrolled increase of these machines. The purchase and conduct of which is not subject to any control and the facthat no driving license is required fromits users. In our study the time between trauma and admission was less than 6 hours in $70.5 \%$ of cases during our study period at the emergency hostingservice. The mean duration was $5.4 \pm 13.87$ hours with extreme going from 1 hour to 22 hours. Olatoundji et al. [14] found an average delay of 2 days with extremes of 15 minutes and 13 days. This result could be explained by the absence of pre-hospital medicine in our country and by the fact that the collection and transport is provided by fire fighters who have limited means in terms of ambulance for the transport of patients to the hospital center.

Of the 200 patients, 198 patients presented with two (2) associated lesions (99\%) and (2) patients (1\%) with three (3) associated lesions. The poly traumatized patients have $37.5 \%$ lesions associated with head trauma plus limb trauma and $25 \%$ with head trauma associated with abdominal trauma and $17 \%$ thoracic + abdominal trauma. Diakité et al. [6] found $48.5 \%$ of head trauma followed by $39.5 \%$ of Polytraumatized, and Diango et al. [7] Mangane et al. [8] found respectively $58.9 \%$ and $48.5 \%$ of trauma cranial. This predominance of cranial lesions could be explained by the fact that two-wheeled vehicles are the most involved in the accident on the one hand and the non-wearing of helmets that authorities could not impose on users. During our study period at the emergency hosting service, $79 \%$ of polytraumatized patients received surgical control damage and were corded a mortality of $31 \%$. Patients among the patients died $51.1 \%$ presented a hemorrhagic shock and $22.6 \%$ a respiratory failure. Olatoundji et al. [14], Diango et al. [7] and Coulibaly et al. [9], avaient retrouvéhad found respectively a mortality of $17.5 \%, 22.6 \%$ and $30 \%$. This mortality rate could be explained by the absence of pre-hospital care, the seriousness of the clinical picture of some patients, the lack of qualified personnel to take charge of polytrauma patients, by the lack of material and medical means likely to improve the care and increase the chances of follow-up of polytraumatized.

\section{Conclusion}

Polytraumaa clinical situation is responsible for multiple lesion associations 
putting the patient's vital prognosis at stake. Haemorrhagic shock is the origin of the mortality raisied. The establishment of a protocolized and rigorous diagnosis system of apre-hospital medicine will reduce the morbi-mortality.

\section{References}

[1] Maurette, P., Masson, F., Nicaud, V., Cazaugade, M., Garros, B., Tiret, L., Thicoipe, M. and Erny, P. (1992) Posttraumaticdisablement: A Prospective Study of Impairment, Disability, and Handicap. Journal of Trauma, 33, 728-736.

[2] Kauvar, D.S. and Wade, C.E. (2005) The Epidemiology and Modern Management of Traumatic Hemorrhage: US and International Perspectives. Critical Care, 9, S1. https://doi.org/10.1186/cc3779

[3] Patel, A. (1976) Polytraumatisé. Masson, Paris.

[4] Sauaia, A., Moore, F.A., Moore, E.E., Moser, K.S., Brennan, R., Read, R.A. and Pons, P.T. (1995) Epidemiology of Trauma Deaths : Areassessment. Journal of Trauma, 38, 185-193. https://doi.org/10.1097/00005373-199502000-00006

[5] OMS (2015) Département Prise en charge des maladies non transmissibles, handicap et prévention de la violence et des traumatismes. Rapport de situation sur la sécurité routière dans le monde, Genève, 1-3.

[6] Diakite, A.K., Anzilania, Diaby and Camara, N.D. (2005) Mortalité par accident de la voie publique au chu-donka. Mali Médical, 20, 17-19.

[7] Diango, D., Ag Iknanea, A., Beye, S.A., Tall, F., Diani, N., Coulibaly, Y. and Diallo, A. (2011) Aspects épidemiocliniques des accidents de voie publique au service d'accueil des urgences chu Gabriel Toure Bamako. Mali Médical, 26, 13-16.

[8] Mangané, M.I., Almeimoune, A.H., Diop, T.H.M., Dembelé, A.S., Touré, M., Konaté, M., Togo, A., Traoré, A. and Diango. M.D. (2016) Traumatismes au Service d'Accueil des Urgences (SAU) du CHU Gabriel Touré de Bamako. Ramur, 21, 16-20.

[9] Coulibaly, Y., Mp, E., Diallo, A., et al. (2004) Le Traumatisme crânien à L'hôpital du Point G : A propos de 80 cas. Mali Médical, 19, 28-31.

[10] Bahloul, M., Chelly, H., Ben Hmida, M., et al. (2004) Prognosis of Traumatic Head Injury in South Tunisia: A multivariateAnalysis of 437 Cases. Journal of Trauma and Acute Care Surgery, 57, 255-261. https://doi.org/10.1097/01.TA.0000083004.35231.1E

[11] Wu, X., Hu, J., Zhuo, L., et al. (2008) Epidemiology of Traumaticbraininjury in Eastern China, 2004: A Prospective Large Case Study. Journal of Trauma and Acute Care Surgery, 64, 1313-1319.

[12] Privat, J.M., Marty Double, C., et al. (1979) Etude anatomo-clinique du syndrome du traumatisme crânien grave [Anatomo-Clinical Study in Severe Head Injury]. Revue d Electroencéphalographie et de Neurophysiologie Clinique, 9, 109-115. https://doi.org/10.1016/S0370-4475(79)80065-9

[13] Kanikomo, D., sogoba, Y., Dama, M., Coulibaly, O. and Diarra, M.S. (2015) Etude épidémiologique, clinique et thérapeutique des fractures embarrures du crâne à propos de 72 cas dans le service de neurochirurgie du CHU Gabriel Toure. Mali Médical, 30, 7-12.

[14] Fatiga, O.H., Mensah, E., Salako, A.A., Babio, R., de Tove, K.M.S. and Gandaho, P. (2011) Aspects cliniques et radio-anatomiques des traumatismes cranio-encéphaliques par accident de la circulation dans un centre hospitalier au bénin. La Tunisie Médical, 89, 837-840. 
[15] Chiu, W.T., Yeh, K.H., Li, Y.C., et al. (1997) Traumatic Brain Injury Registry in Taiwan. Neurological Research, 19, 261-264. https://doi.org/10.1080/01616412.1997.11740811

[16] Suriyawongpaisal, P. and Kanchanusut, S. (2003) Road Traffic Injuries in Thailand: Trends, Selected Underlying Determinants and Status of Intervention. Injury Control and Safety Promotion, 10, 95-104.

https://doi.org/10.1076/icsp.10.1.95.14110 